\title{
Enhancement of absorption and bioavailability of echinacoside by verapamil or clove oil
}

\author{
This article was published in the following Dove Press journal: \\ Drug Design, Development and Therapy \\ 14 August 2015 \\ Number of times this article has been viewed
}

\author{
Jin-Yang Shen ${ }^{1, *}$ \\ Xiao-Lin Yang ${ }^{2, *}$ \\ Zhong-Lin Yang' \\ Jun-Ping Kou' \\ Fei $\mathrm{Li}^{\prime}$
}

'State Key Laboratory of Natural Medicines, China Pharmaceutical University, ${ }^{2}$ Key Laboratory of Pharmaceutical and Biological Marine Resources Research and Development of Jiangsu Province, Nanjing University of Chinese Medicine, Nanjing, People's Republic of China

*These authors contributed equally to this work
Correspondence: Fei Li

State Key Laboratory of Natural

Medicines, China Pharmaceutical

University, No 24 Tongjia Lane,

Nanjing 210009 , People's Republic of China

Tel +86258327 I382

Email lifeicpu@।63.com;

lifeicpu@hotmail.com

Jun-Ping Kou

State Key Laboratory of Natural

Medicines, China Pharmaceutical

University, 639 Longmian Road, Nanjing

21 II 98, People's Republic of China

Tel +862586I85I58

Email junpingkou@।63.com
Purpose: This present study investigated the absorption kinetics of echinacoside (ECH) in situ and in vitro and its oral bioavailability in rats. Additional aim was to find an agent(s) to promote ECH absorption and oral bioavailability among two efflux proteins and three absorption promoters.

Methods: ECH absorption behaviors were investigated by everted gut sac model in vitro and single-pass intestinal perfusion model in situ. Pharmacokinetics study was performed to investigate the influences of verapamil and clove oil on ECH bioavailability in vivo. All samples were measured at different time intervals by high performance liquid chromatography.

Results: The results showed that the effective permeability coefficient $\left(P_{\text {eff }}\right)$ and apparent permeability coefficient of ECH were $0.83 \times 10^{-6}-3.23 \times 10^{-6} \mathrm{~cm} / \mathrm{s}$ and $2.99 \times 10^{-6}-9.86 \times 10^{-6} \mathrm{~cm} / \mathrm{s}$, respectively. The $P_{\text {eff }}$ among duodenum, jejunum, and ileum were not statistically different, but they were higher than colon $(P<0.01)$, which demonstrated that intestinal ECH absorption was poor and site dependent. Additionally, verapamil and clove oil significantly increased the jejunal $P_{\text {eff }}$ of ECH both in situ and in vitro. Moreover, the bioavailability of ECH in combination with verapamil and clove oil were increased by 1.37 -fold $(P<0.05)$ and 2.36 -fold $(P<0.001)$, respectively, when compared to ECH group. Overall, verapamil and clove oil facilitated ECH absorption and oral bioavailability.

Conclusion: The absorption and bioavailability of ECH were enhanced by verapamil and clove oil, respectively, both in vitro and in vivo. Consequently, the combination of verapamil and clove oil with $\mathrm{ECH}$ will be a promising and effective approach to promote intestinal absorption and oral bioavailability of ECH.

Keywords: intestinal absorption, efflux protein inhibitor, absorption promoter

\section{Introduction}

Echinacoside (ECH, Figure 1), a polyphenolic macromolecular carbohydrate existing in Cistanche tubulosa (Schrenk) R. Wight and other traditional Chinese medicines, ${ }^{1}$ possesses a variety of pharmacological activities, such as antiosteoporosis, ${ }^{1,2}$ vasorelaxation, ${ }^{3}$ neuroprotection, ${ }^{4,5}$ hepatoprotection, ${ }^{6}$ and antioxidant. ${ }^{7}$ Our previous study showed that ECH can effectively stimulate bone regeneration through increasing the ratio of osteoprotegerin and receptor activator of nuclear factor- $\mathrm{\kappa B}$ ligand in MC3T3-E1 cells and in osteoporosis model in rats. ${ }^{1,2}$ However, the oral bioavailability of ECH in rats is only $0.83 \% .{ }^{8}$ Therefore, it is necessary to further investigate the absorption behaviors and characteristics of $\mathrm{ECH}$ and search for the agent(s) to promote the absorption and oral bioavailability of $\mathrm{ECH}$, as well as the possible mechanism(s).

Generally, poor oral bioavailability may result from low intestinal permeability, high metabolism, extensive biliary excretion and chemical instability in 


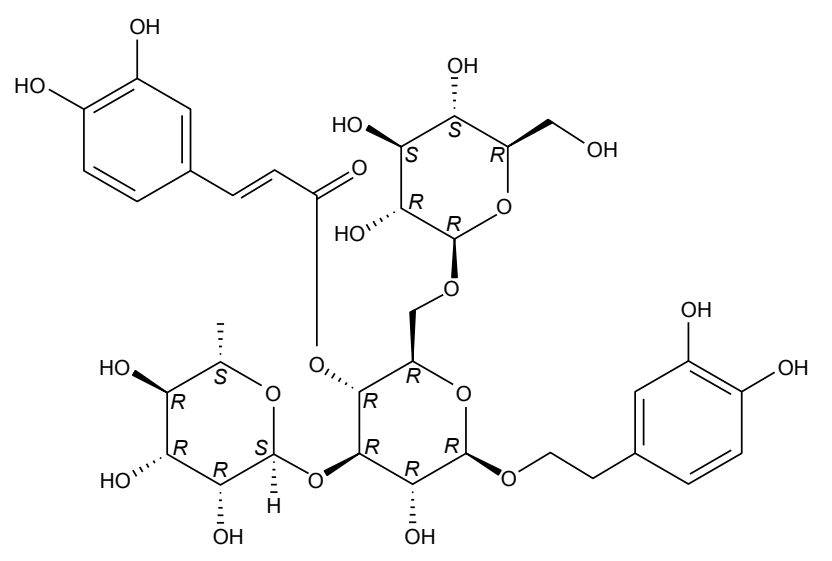

Figure I Chemical structure of $\mathrm{ECH}$.

Abbreviation: $\mathrm{ECH}$, echinacoside.

gastrointestinal juice, and discontent intestinal absorption is one of the most important factors, which count for the low oral bioavailability. ${ }^{9}$ Moreover, some efflux proteins, $P$-glycoprotein $(P$-gp) that belongs to ATP-binding cassette transporters superfamily, ${ }^{10}$ and multidrug resistance protein (MRP) that induced expression in diseases, such as cancer, which results in worsened prognosis as the malignant tissues, ${ }^{11}$ are abundant in the human intestines, and play a significant role in drug absorption, transport, and bioavailability. ${ }^{12}$ In addition, some plant essential oils could act as absorption promoters to improve intestinal absorption of active ingredients from traditional Chinese medicines. ${ }^{13-15}$ Borneol, ${ }^{15-17}$ pennyroyal, ${ }^{15}$ and clove oil ${ }^{15,18}$ are all natural plant essential oils and have been reported as absorption promoters used in many articles.

In this study, we evaluated two efflux protein inhibitors (verapamil, $P$-gp inhibitor; ${ }^{19}$ probenecid, MRP inhibitor ${ }^{20}$ ), and three absorption-enhancing agents (borneol, pennyroyal, and clove oil) by everted gut sac model in vitro and singlepass intestinal perfusion model in situ, and evaluated the influences of verapamil and clove oil on ECH oral bioavailability. Finally, we found out that verapamil and clove oil increased intestinal absorption and oral bioavailability of $\mathrm{ECH}$ and probed the potential mechanism(s) preliminary.

\section{Materials and methods Materials and reagents}

$\mathrm{ECH}$, borneol, verapamil, and probenecid were bought from Chinese National Institute for the control of pharmaceutical and biological products (Beijing, People's Republic of China). Pennyroyal and clove oil were purchased from Nanjing Chemical Reagent Co., Ltd (Nanjing, People's Republic of China). Methanol of chromatographic grade was obtained from Hanbon Science and Technology (Huai'an, People's Republic of China). All of the other chemicals and solvents were of analytical reagent grade.

The perfusion solution was Krebs-Ringer (K-R) buffer solution, which contained $7.8 \mathrm{~g} \mathrm{NaCl}, 0.35 \mathrm{~g} \mathrm{KCl}, 1.37 \mathrm{~g}$ $\mathrm{NaHCO}_{3}, 0.02 \mathrm{~g} \mathrm{MgCl}_{2}, 0.32 \mathrm{~g} \mathrm{NaH}_{2} \mathrm{PO}_{4}$, and 1.48 g glucose in $1,000 \mathrm{~mL}$ deionized water.

\section{Animals}

Male Sprague Dawley (SD) rats (200-250 g) were obtained from the Animal Center of Nantong University (Nantong, People's Republic of China), and housed in cages under controlled humidity at room temperature $\left(28^{\circ} \mathrm{C} \pm 2^{\circ} \mathrm{C}\right)$. Twelvehour light/dark cycle was maintained, and standard diet and water were available ad libitum. Animal experiments were conducted after due clearance from Animals Ethics Committee of the University.

\section{Preparation of everted gut sac model in vitro}

Everted gut sac methods were performed as described previously. ${ }^{13}$ Briefly, 16-24 hours fasted SD rats were anesthetized with $20 \%$ urethane (ip $1.3 \mathrm{~g} / \mathrm{kg}$ ). The abdomen was opened by a midline incision $(2-3 \mathrm{~cm})$, and then duodenums, jejunums, ileums, and colons $(\sim 10 \mathrm{~cm}$ each) were rapidly removed from the anesthetized rat and placed quickly in beakers with $\mathrm{K}-\mathrm{R}$ buffer solution on ice. The animals were sacrificed by cervical dislocation before recovering from anesthesia. All intestinal segments were immediately flushed with ice-cold K-R buffer solution to remove the intestinal contents and the underlying mesenterium. Each intestinal segment was tied at one end, everted with a smooth glass rod, and blotted dry to remove mucus. The everted sacs were ligated with silk thread to a hollow glass tube at the other end for sampling. The sacs were filled with $2 \mathrm{~mL}$ of $\mathrm{K}-\mathrm{R}$ buffer solution and then incubated in different donor solutions $\left(37^{\circ} \mathrm{C}\right.$, the $\mathrm{K}-\mathrm{R}$ buffer solution with different ECH concentrations), which were aerated with $5 \% \mathrm{CO}_{2}$ and $95 \% \mathrm{O}_{2}$. About $0.5 \mathrm{~mL}$ of samples were taken out from the internal medium completely at different time intervals (15 minutes, 30 minutes, 45 minutes, 60 minutes, 75 minutes, 90 minutes), and also equivalent fresh $\mathrm{K}-\mathrm{R}$ buffers were added to the sacs.

\section{Preparation of single-pass intestinal perfusion model in situ}

Single-pass intestinal perfusion methods in situ were performed according to the previous report. ${ }^{14} \mathrm{SD}$ rats were anesthetized with $20 \%$ urethane (ip $1.3 \mathrm{~g} / \mathrm{kg}$ ) and placed 
under an infrared lamp to maintain normal body temperature. The abdominal cavity was opened, and the desired intestinal segments (about $10 \mathrm{~cm}$ ) were pulled out carefully to maintain an intact blood supply. The intestinal segments were cannulated on two ends with glass tubes and rinsed with $37^{\circ} \mathrm{C}$ normal saline solution until the outlet solution was visually clear. Subsequently, $\mathrm{K}-\mathrm{R}$ solution containing ECH was perfused through the loop at a flow rate of $0.2 \mathrm{~mL} / \mathrm{min}$ for 30 minutes to get steady-state condition. Samples were periodically collected with a weighed tube at intervals of 15 minutes and lasted for 90 minutes. After experiment, the inlet and outlet tubes were weighed and animals were sacrificed by cervical dislocation.

\section{Study of stability and nonspecific binding of $\mathrm{ECH}$}

Preliminary studies were necessary to ensure that the loss of drug from the perfusion was due to absorption, but not other causes (eg, degradation or nonspecific binging to intestinal wall and tubes). ${ }^{21}$ The stability of ECH was tested by incubating $\mathrm{ECH}$ in $\mathrm{K}-\mathrm{R}$ buffer and intestinal at $37^{\circ} \mathrm{C}$ for 2 hours. Nonspecific binding of ECH was detected by incubating ECH solution with the intestinal walls and rubber tubes.

\section{Absorption study of ECH in different intestinal segments}

Everted gut sac model in vitro and single-pass intestinal perfusion model in situ were both used to test whether the intestinal absorption of ECH exhibit site dependence. The ECH solution at the same concentration $(0.09 \mathrm{mg} / \mathrm{mL})$ was perfused through the duodenum, jejunum, ileum, and colon to investigate the appropriate segment of ECH absorption.

\section{Absorption study of $\mathrm{ECH}$ in different concentrations}

In order to determine the influence of different $\mathrm{ECH}$ concentrations on its absorptive transport and intestinal permeability, solutions containing three concentrations of ECH $(0.03 \mathrm{mg} / \mathrm{mL}, 0.09 \mathrm{mg} / \mathrm{mL}, 0.27 \mathrm{mg} / \mathrm{mL})$ were administrated into the jejunal segments in in vitro and in situ studies, respectively, as described earlier.

\section{Effect of efflux protein inhibitors absorption promoters on intestinal absorption behavior of $\mathrm{ECH}$}

The influence of $P$-gp and MRP on the intestinal absorption behaviors of ECH was studied by in vitro and in situ methods. The solution containing $0.2 \mathrm{mg} / \mathrm{mL}$ verapamil $(P$-gp inhibitor) and $0.09 \mathrm{mg} / \mathrm{mL} \mathrm{ECH}$ and $0.2 \mathrm{mg} / \mathrm{mL}$ probenecid (MRP inhibitor) and $0.09 \mathrm{mg} / \mathrm{mL}$ ECH were administrated into jejunal segments, respectively as described earlier.

The intestinal absorption properties of ECH with or without absorption promoters were determined utilizing both everted gut sac model in vitro and single-pass intestinal perfusion model in situ. Borneol $(0.1 \mathrm{mg} / \mathrm{mL})$, pennyroyal $(0.1 \mathrm{~mL} / \mathrm{mL})$, and clove oil $(0.1 \mathrm{~mL} / \mathrm{mL})$, together with $\mathrm{ECH}(0.09 \mathrm{mg} / \mathrm{mL})$, were perfused through the rat jejunum, respectively as described earlier.

\section{Calculation of absorption parameters in vitro and in situ}

Permeation flux $(F, \mu \mathrm{g} / \mathrm{s})$, apparent permeability coefficient $\left(P_{\text {app }}, \mathrm{cm} / \mathrm{s}\right)$, intestinal effective permeability coefficient $\left(P_{\text {eff }}, \mathrm{cm} / \mathrm{s}\right)$ of drugs were calculated by the following equations ${ }^{22,23}$ :

$$
\begin{gathered}
F=d Q / d t \\
K a=\left(1-C_{\text {out }} Q_{\text {out }} / C_{\text {in }} Q_{\text {in }}\right) \times Q / V \\
P_{\text {app }}=(d Q / d t) \times\left(1 / A C_{0}\right) \\
P_{\text {eff }}=-\mathrm{Q} \times \ln \left(C_{\text {out }} Q_{\text {out }} / C_{\text {in }} Q_{\text {in }}\right) / 2 \pi r l
\end{gathered}
$$

where $(d Q / d t)$ is the flux of ECH from the mucosal-to-serosal side of the mucosa; $A\left(\mathrm{~cm}^{2}\right)$ is the surface of the membrane and $C_{0}(\mathrm{mg} / \mathrm{mL})$ is the initial concentration of ECH in the donor compartment; $Q(\mathrm{~mL} / \mathrm{min})$ is the volume flow rate of the intestine; $C_{\text {in }}(\mathrm{mg} / \mathrm{mL})$ and $C_{\text {out }}(\mathrm{mg} / \mathrm{mL})$ are the inlet and outlet concentration of drug in perfusion buffer in perfusion buffer, respectively; and the density of perfusion buffer was $1.0 \mathrm{~g} / \mathrm{mL}$ both at inlet and outlet; $Q_{\text {in }}(\mathrm{mL})$ and $Q_{\text {out }}(\mathrm{mL})$ are the volume of perfusion buffer volume at inlet and outlet, respectively; $V\left(\mathrm{~cm}^{3}\right)$ is the volumes of perfusion segment; $r$ is the jejunum segment luminal radius and $l$ is the mean length of perfused jejunum segment.

\section{Pharmacokinetic study}

Eighteen SD rats were randomly selected and divided into three groups $(\mathrm{n}=6)$ for oral administration as follows: group I, ECH $(120 \mathrm{mg} / \mathrm{kg})$; group II $(\mathrm{ECH}+\mathrm{V}), \mathrm{ECH}$ $(120 \mathrm{mg} / \mathrm{kg})+$ verapamil $(0.2 \mathrm{mg} / \mathrm{mL})$; group III $(\mathrm{ECH}+\mathrm{C})$, $\mathrm{ECH}(120 \mathrm{mg} / \mathrm{kg})+$ clove oil $(0.1 \mathrm{~mL} / \mathrm{mL})$. After overnight fasting, rats were orally administered with $\mathrm{ECH}$ and its combinations. Blood samples $(0.5 \mathrm{~mL})$ were taken from the eye ground veins at different time intervals of 0 minute, 
5 minutes, 15 minutes, 30 minutes, 60 minutes, 120 minutes, 180 minutes, 240 minutes, 360 minutes, 600 minutes, and 960 minutes, then centrifuged at 4,000 rpm for 15 minutes and separated the plasma and were stored at $-20^{\circ} \mathrm{C}$ until further analysis by high performance liquid chromatography (HPLC) method as reported. ${ }^{24}$ The bioavailability of three groups was evaluated by DAS 2.1.1 software (Shanghai, People's Republic of China).

\section{Statistical analyses}

The results were all presented as mean \pm standard deviation. Data were analyzed by one-way analysis of variance and LSD $t$-test using SPSS (Version 15.0, SPSS Inc., Chicago, IL, USA). A probability level of $P<0.05$ was considered to be significantly different.

\section{Results}

\section{Stability and nonspecific binding of $\mathrm{ECH}$}

$\mathrm{ECH}$ was found to be stable both in $\mathrm{K}-\mathrm{R}$ buffer solution and intestinal perfusate in 2-hour incubation. The results showed that no ECH was absorbed by intestinal wall and tubes in everted gut sac and single-pass intestinal perfusion experiment (Figure 2). The incubation results suggested that any loss of drug from the perfusion should be attributed to intestinal absorption.

\section{Site dependence of ECH absorption}

The absorption parameters of ECH in four different intestinal segments were evaluated by everted gut sac method in vitro as shown in Figure 3, there was no significant statistical difference in $F$ and $P_{\text {app }}$ among duodenum,

A

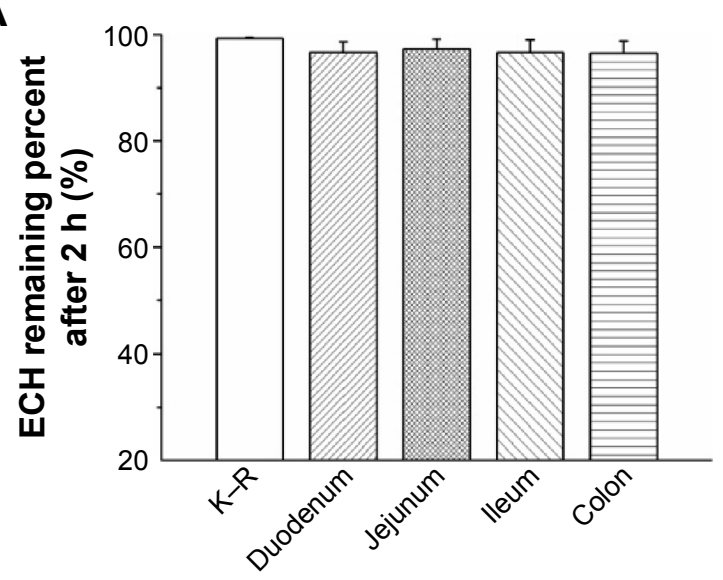

jejunum, and ileum $(P>0.05)$. Both $F$ and $P_{\text {app }}$ of these three segments were higher than colon $(P<0.01)$. The in vitro results demonstrated that $\mathrm{ECH}$ was mostly absorbed in the small intestine rather than the colon, though the absorption of ECH had no specificity among the above three small intestine segments.

Data gained in the single-pass intestinal perfusion in situ data also illustrated that the small intestine was the appropriate segment of absorption for ECH, and Figure 4 showed that the absorption rate constant $(\mathrm{Ka})$ and $P_{\text {eff }}$ of ECH from duodenum, jejunum, and ileum were significantly higher, compared to colon $(P<0.01)$. Additionally, no significant statistical differences were observed among these three segments $(P>0.05)$, and the result were consistent with in vitro results, which suggested that $\mathrm{ECH}$ had higher absorption in small intestine segments compared to colon segment.

\section{Concentration dependence of $\mathrm{ECH}$ absorption}

Jejunum was selected to study concentration dependence of $\mathrm{ECH}$ absorption in in vitro model. As shown in Figure 5A, compared to $0.03 \mathrm{mg} / \mathrm{mL}$ group, $F$ and $P_{\text {app }}$ were lower than $0.09 \mathrm{mg} / \mathrm{mL}$ and $0.27 \mathrm{mg} / \mathrm{mL}(P>0.05)$, but there was no statistical difference between the above concentration groups.

Figure 5B depicted the absorption parameters $K a$ and $P_{\text {eff }}$ evaluated by single-pass intestinal perfusion model in situ. The results showed $K a$ and $P_{\text {eff }}$ in $0.09 \mathrm{mg} / \mathrm{mL}$ and $0.27 \mathrm{mg} / \mathrm{mL}$ group were significantly higher than $0.03 \mathrm{mg} / \mathrm{mL}$ group $(P<0.05)$. The above results indicated that ECH might cross the intestinal barrier by carrier-mediated uptake/efflux pathways in jejunum.
B

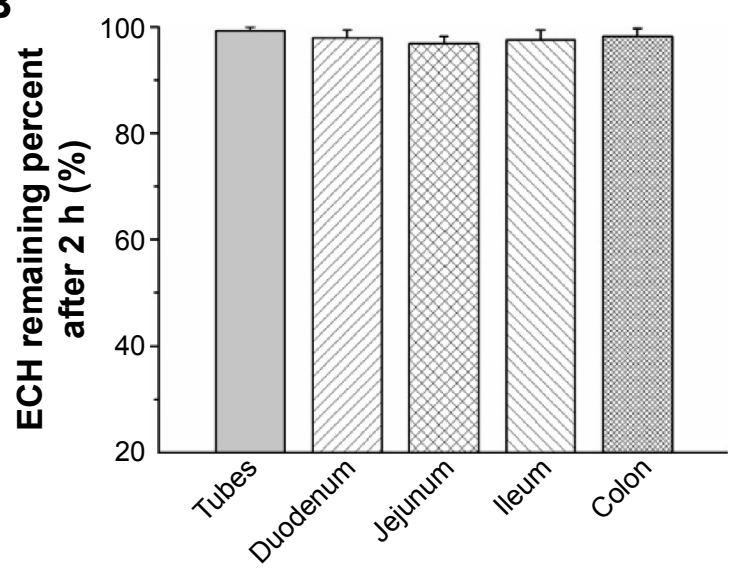

Figure 2 Stability and nonspecific binding of $\mathrm{ECH}$.

Notes: $(\mathbf{A}) \mathrm{ECH}$ remaining percent after $2 \mathrm{~h}$ in $\mathrm{K}-\mathrm{R}$ buffer solution and homogenates of rat intestinal segments. (B) Binding of $\mathrm{ECH}$ to tubes and different sections of intestine after 2-h incubation. Results were shown as mean $\pm S D$ ( $n=3$ in each group).

Abbreviations: $\mathrm{ECH}$, echinacoside; h, hours; K-R, Krebs-Ringer; SD, standard deviation. 
A

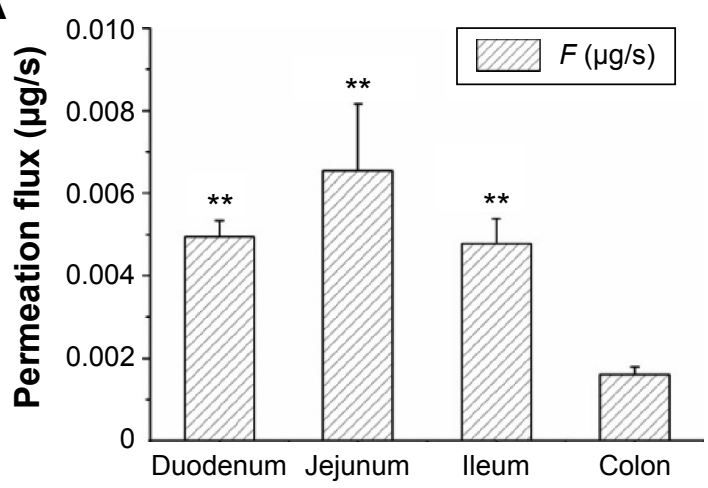

B

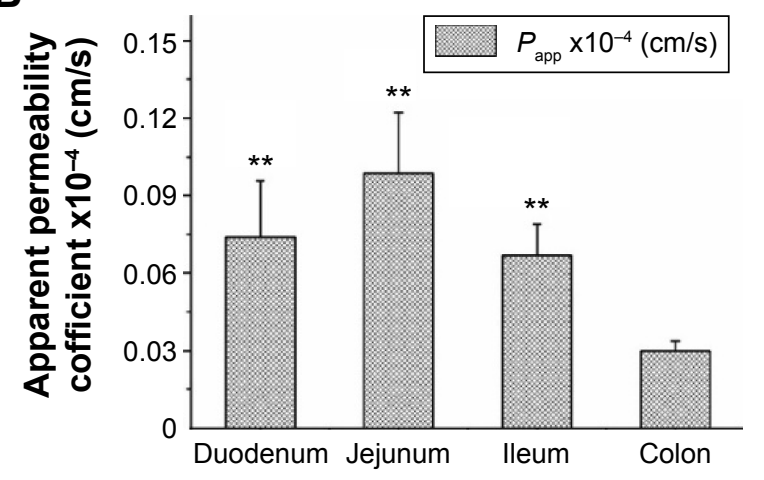

Figure 3 Site dependence of ECH absorption evaluated by in vitro everted gut sac model.

Notes: (A) Permeation flux of ECH in four different intestinal segments: duodenum, jejunum, ileum, and colon. (B) Apparent permeability coefficient of ECH in four intestinal segments such as duodenum, jejunum, ileum, and colon. Results were shown as mean $\pm S D$ ( $n=6$ in each group). $* * P<0.0$ I versus colon group.

Abbreviations: $\mathrm{ECH}$, echinacoside; $\mathrm{SD}$, standard deviation; $P_{\text {app }}$, apparent permeability coefficient; $F$, permeation flux.

\section{Effect of efflux protein inhibitors and absorption promoters on $\mathrm{ECH}$ absorption}

Some efflux proteins, such as $P$-gp and MRP, had an important influence on drug accumulation and transport in intestine. ${ }^{25}$ Therefore, it was necessary to evaluate the influence of verapamil ( $P$-gp inhibitor) and probenecid (MRP inhibitor) on the absorption parameters of ECH. Figure 6A showed the changes of ECH absorption parameters $F$ and $P_{\text {app }}$ between the groups with or without verapamil and probenecid in in vitro everted gut sac system. Compared to control group, the $F$ and $P_{\text {app }}$ in verapamil group were significantly increased $(P<0.05)$, and which implicated that ECH might be the substrate of $P$-gp. Besides, as shown in Figure 6B, the $K a$ and $P_{\text {eff }}$ in verapamil group in in situ model were much higher $(P<0.01)$ in comparison with control group, and which was consistent with the in vitro results, and similarly suggesting that ECH was the substrate of $P$-gp.

\section{A}

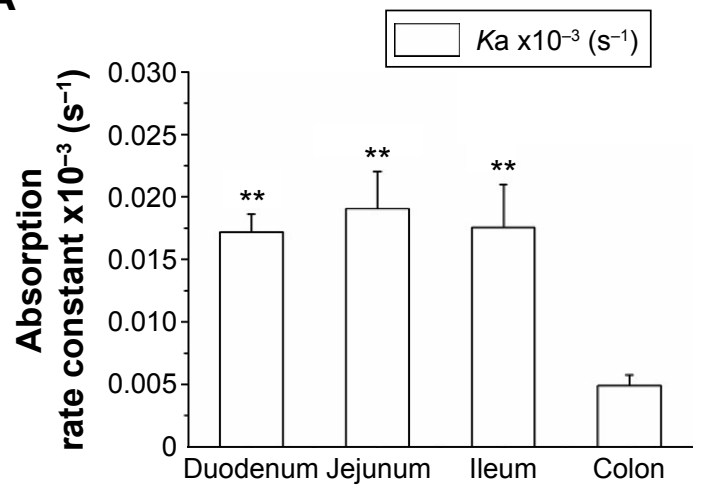

Some essential plant oils could improve the intestinal absorption of saponins with low intestinal permeability. ${ }^{13}$ In this study, the influence of borneol, pennyroyal, and clove oil on the ECH intestinal absorption properties were investigated by using in vitro and in situ experiment and the potential absorption enhancer was studied. The absorption parameters were presented in Figure 7 (Figure 7A, in vitro; Figure 7B, in situ). These results showed that the intestinal absorption of ECH was significantly increased by clove oil compared to control group $(P<0.05)$. However, neither borneol nor pennyroyal had significant absorption enhancing effect.

\section{Pharmacokinetic study}

Mean plasma concentration-time profiles were illustrated in Figure 8 and the pharmacokinetic parameters $C_{\max }, T_{\max }$, $\mathrm{MRT}_{0-t}, \mathrm{MRT}_{0-\infty}, \mathrm{AUC}_{0-24}, \mathrm{AUC}_{0-\infty}$, and $\mathrm{CLz} / F$ of $\mathrm{ECH}$ alone and its combination with verapamil and clove oil in rat plasma were summarized in Table 1, respectively.

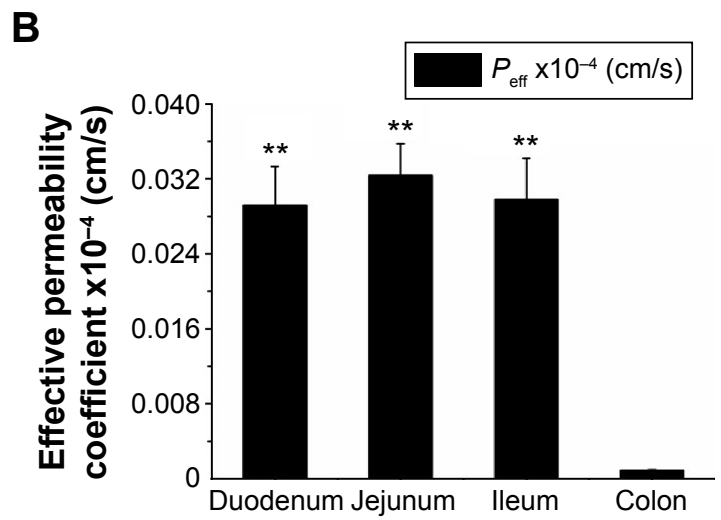

Figure 4 Site dependence of ECH absorption evaluated by in situ single-pass intestinal perfusion model.

Notes: (A) Absorption rate constant, Ka. (B) Effective permeability coefficient, $P_{\text {eff }}$ Results were shown as mean $\pm S D$ ( $n=6$ in each group). ${ }^{* * P}<0.0$ I versus colon group. Abbreviations: $\mathrm{ECH}$, echinacoside; $\mathrm{SD}$, standard deviation. 

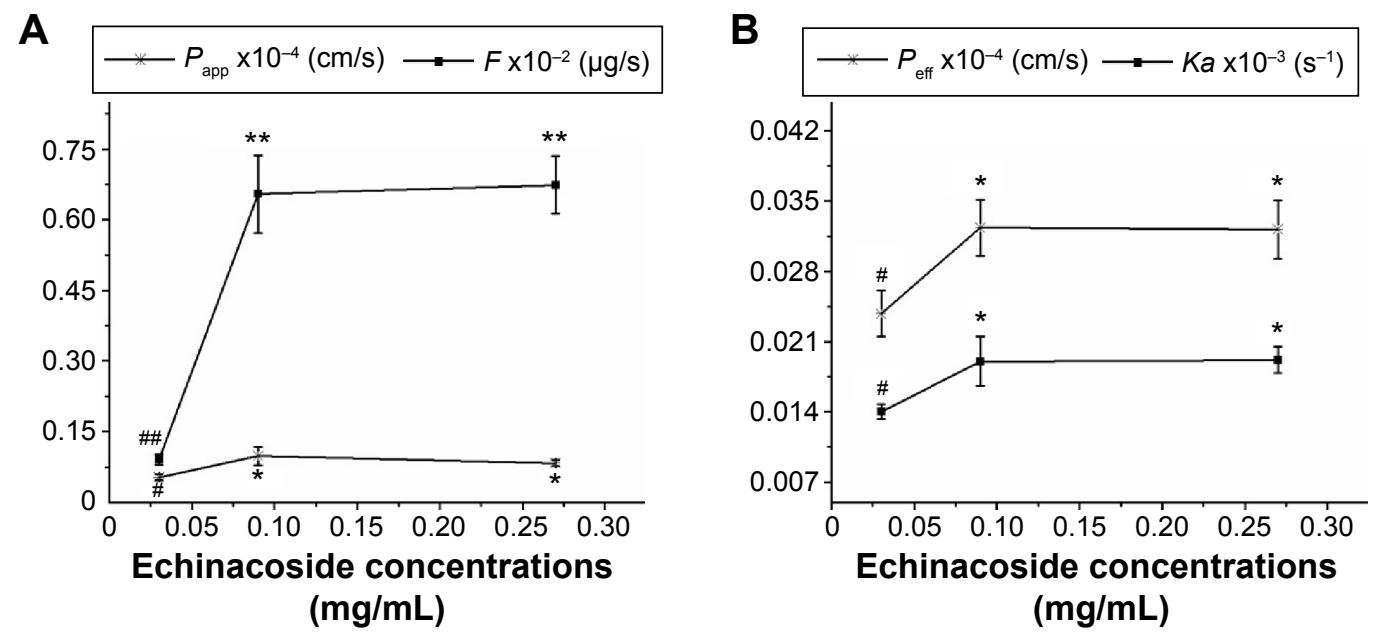

Figure 5 Absorption parameters of $\mathrm{ECH}$ in different concentrations.

Notes: (A) $F$ and $P_{\text {cp }}$ came from in vitro everted gut sac experiment. (B) $K a$ and $P_{\text {eff }}$ came from in situ single-pass intestinal perfusion experiment. Results were shown as mean $\pm S D$ ( $n=6$ in each group). ${ }^{*} P<0.05$, ${ }^{* * P}<0.0$ l versus the low concentration group. ${ }^{\#} P<0.05,{ }^{\#} P<0.01$ versus the middle concentration group.

Abbreviations: $\mathrm{ECH}$, echinacoside; $P_{\text {app }}$, apparent permeability coefficient; $P_{\text {eff }}$ effective permeability coefficient; SD, standard deviation; Ka, absorption rate constant; $F$, permeation flux.

The bioavailability of ECH after oral administration in combination with verapamil and clove oil has been significantly increased by 1.37 -fold $(P<0.05)$ and 2.36-fold $(P<0.001)$, when compared to ECH alone. Furthermore, the $C_{\max }$ value of $\mathrm{ECH}+\mathrm{V}$ and $\mathrm{ECH}+\mathrm{C}$ were about 1.4-fold and 2.58-fold higher than ECH. From these results, the pharmacokinetics was all fitted two-compartment model after a single dose of $\mathrm{ECH}$ and with its combination. The mechanism(s) of promoting the bioavailability of ECH by verapamil and clove oil will be further investigated in the future study.

\section{Discussion}

Various in vitro, in situ, and in vivo models have been developed to evaluate drug absorption in intestine, such as Caco-2

A

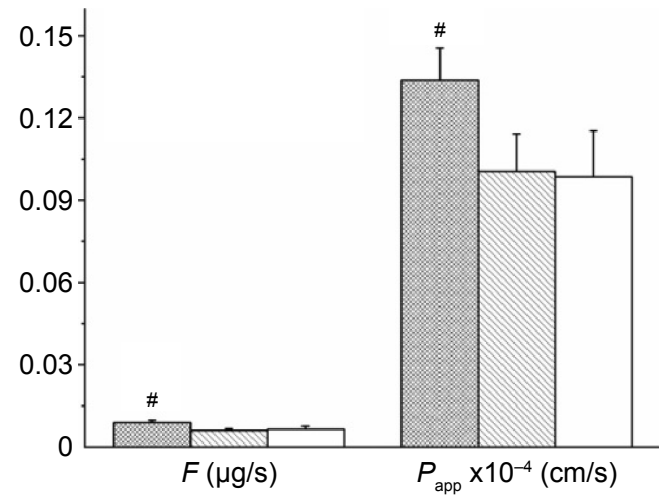

cell monolayer model, everted gut sac model, single-pass intestinal perfusion model, and each model has its merits and demerits. Therefore, simultaneous utilization of two independent models as a cross-validation of experimental system would produce reliable values when studying intestinal absorption. ${ }^{26}$ In this present study, everted gut sac model in vitro and single-pass intestinal perfusion in situ were employed to study the intestinal absorption characteristics of $\mathrm{ECH}$ and to obtain reliable results. The consistent conclusions were obtained from the in vitro and in situ models in this research; however, the statistical significances of parameters among some paired groups were different, which was caused by different prediction accuracy of the two models, and this was in accordance with the previous report. ${ }^{26}$
B

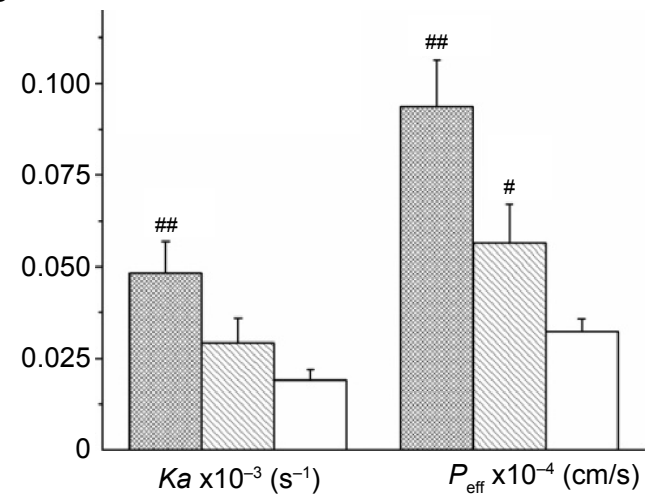

Figure 6 Absorption parameters of ECH in the absence or presence of two different efflux protein inhibitors.

Notes: (A) $F$ and $P_{\text {app }}$ came from in vitro everted gut sac experiment. (B) $K a$ and $P_{\text {eff }}$ came from in situ single-pass intestinal perfusion experiment. Results were shown as mean $\pm S D$ ( $n=6$ in each group). ${ }^{\#} P<0.05,{ }^{\#} P<0.0$ l versus the control group.

Abbreviations: $\mathrm{ECH}$, echinacoside; $P_{\text {app }}$, apparent permeability coefficient; $P_{\text {eff }}$ effective permeability coefficient; SD, standard deviation; Ka, absorption rate constant; $F$, permeation flux. 

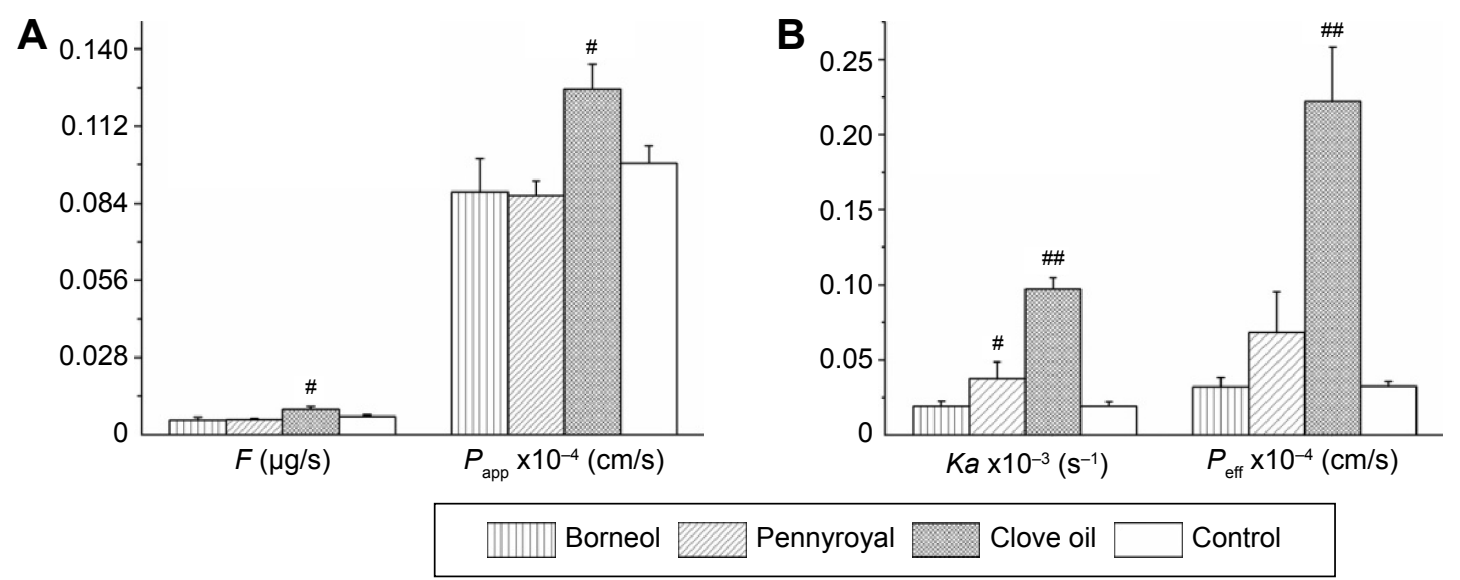

Figure 7 Absorption parameters of $\mathrm{ECH}$ in the absence or presence of three different absorption promoters.

Notes: (A) $F$ and $P_{\text {app }}$ came from in vitro everted gut sac experiment. (B) $K a$ and $P_{\text {eff }}$ came from in situ single-pass intestinal perfusion experiment. Results were shown as mean $\pm S D$ ( $n=6$ in each group). ${ }^{\#} P<0.05,{ }^{\#} P<0.01$ versus the control group.

Abbreviations: $\mathrm{ECH}$, echinacoside; $P_{\text {app }}$, apparent permeability coefficient; $P_{\text {eff }}$ effective permeability coefficient; SD, standard deviation; Ka, absorption rate constant; $F$, permeation flux.

Orally administrated drug may cross the intestinal barrier by single pathway or combination of several pathways, including passive transcellular diffusion, passive paracellular diffusion, and carrier-mediated uptake or efflux transport. ${ }^{27}$ In the present report, there was no concentration dependence of ECH absorption, and a saturable absorption appeared when the concentration was higher than $0.09 \mathrm{mg} / \mathrm{mL}$. The concentration independence coupled with the saturable absorption suggested that ECH was transported via carrier-mediated uptake/efflux pathways in jejunum. Moreover, verapamil could significantly improve the absorption of $\mathrm{ECH}$, and which indicated that ECH was the substrate of $P$-gp. In order to identify the other specific protein involved in the carriermediated process, experiments about cells transfected with the gene coding need to be conducted in future. ${ }^{21}$

Site dependence of ECH absorption was observed based on the in vitro and in situ experiments. The lowest absorption was observed in colon, which was consistent with many

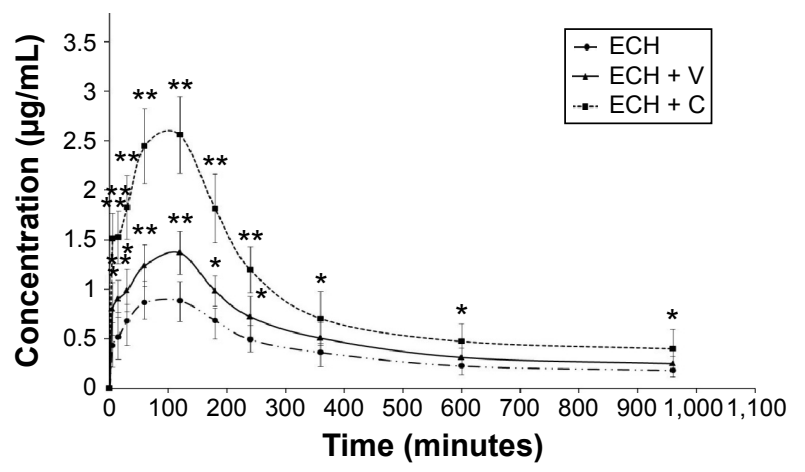

Figure 8 Plasma concentration profiles in rats after oral administrations of ECH and $\mathrm{ECH}$ with combinations.

Notes: Results were shown as mean \pm SD ( $n=6$ in each group). $* p<0.05 ; * * p<0.0$ I versus $\mathrm{ECH}$ group.

Abbreviations: $\mathrm{ECH}$, echinacoside; SD, standard deviation; $\mathrm{V}$, verapamil; C, clove oil. previous reports. ${ }^{13,14}$ This might be due to a decreased total surface area of membrane and increased tightness of the epithelium in the colonic region. ${ }^{28,29}$ Moreover, it was suitable to prepare sustained release preparation to extend the remained time of ECH in small intestine and to improve the absorption.

According to biopharmaceutics classification system, drugs with $P_{\text {eff }}<0.03 \times 10^{-4} \mathrm{~cm} / \mathrm{s}$ in the small intestine of rat on in situ perfusion model are regarded as poor absorption, whereas $P_{\text {eff }}>0.2 \times 10^{-4} \mathrm{~cm} / \mathrm{s}$ are complete absorption. ${ }^{30}$ The highest permeability of ECH in the whole intestine was $3.23 \times 10^{-6} \mathrm{~cm} / \mathrm{s}$, and which indicated that intestinal absorption of ECH was poor, and this result was in accordance with the result from the study conducted on a Caco-2 cell monolayer model. ${ }^{31}$ In addition, low intestinal permeability of ECH might be a count for its poor oral bioavailability.

Until now, some plant essential oils have been adopted to improve the intestinal absorption of active ingredients in traditional Chinese medicine. ${ }^{13-15}$ In the present research, clove oil, extracted from Eugenia caryophyllata and consisted of eugenol, acetyleugenol, and other terpenes with various carbon numbers, was demonstrated to have a promotion on the intestinal absorption of ECH across the jejunal barrier. ${ }^{18}$ Our results agreed with some previous studies that clove oil could improve oral absorption of polysaccharides and increase some drugs' transdermal penetration. ${ }^{15,18}$ The potential mechanism(s) of clove oil for improving absorption may alter lipid phase of the intestinal mucous membrane, accelerate fluidity of polar head group regions of cell membranes, and loosen the intercellular tight junction in intestinal tract. ${ }^{13,14}$ However, the exact mechanism(s) was not fully understood and deserved further investigation. 
Table I The main pharmacokinetic parameters of echinacoside with absorption promoters clove oil and efflux protein inhibitors verapamil in rats plasma (mean $\pm S D, n=6)$

\begin{tabular}{llll}
\hline Parameters & ECH & ECH + verapamil & ECH + clove oil \\
\hline $\mathrm{AUC}_{0-24}(\mu \mathrm{g} / \mathrm{L} \cdot \mathrm{min})$ & $370.744 \pm 48.204$ & $536.555 \pm 49.462^{* *}$ & $899.901 \pm 74.100^{* *}$ \\
$\mathrm{AUC}_{0-\infty}(\mu \mathrm{g} / \mathrm{L} \cdot \mathrm{min})$ & $483.815 \pm 143.336$ & $661.363 \pm 55.12 I^{*}$ & $1,141.271 \pm 286.613^{* *}$ \\
$\mathrm{MRT}_{0-t}(\mathrm{~min})$ & $328.397 \pm 33.452$ & $322.564 \pm 17.958$ & $300.796 \pm 44.939$ \\
$\mathrm{MRT}_{0-\infty}(\mathrm{min})$ & $672.547 \pm 301.549$ & $619.213 \pm 137.42$ & $573.291 \pm 262.976$ \\
$T_{\text {max }}(\mathrm{min})$ & $100.000 \pm 30.984$ & $87.500 \pm 30.619$ & $100.000 \pm 15.492$ \\
$\mathrm{CLz} / \mathrm{F}(\mathrm{min})$ & $262.753 \pm 60.553$ & $182.559 \pm 16.105^{*}$ & $110.007 \pm 23.403^{* *}$ \\
$C_{\max }(\mu \mathrm{g} / \mathrm{L})$ & $1.118 \pm 0.115$ & $1.570 \pm 0.226 * *$ & $2.890 \pm 0.483^{* *}$ \\
\hline
\end{tabular}

Notes: $* P<0.05, * * P<0.01$ versus the $\mathrm{ECH}$ group.

Abbreviations: SD, standard deviation; $\mathrm{ECH}$, echinacoside; min, minute; $\mathrm{C}_{\max }$, peak concentration; $\mathrm{T}_{\max }$, peak time; $M \mathrm{MRT}$, mean retention time; $\mathrm{AUC} \mathrm{C}_{0-24}$, area under concentration-time curve from 0 to $24 \mathrm{~h} ; \mathrm{AUC}_{0-\infty}$, area under concentration-time curve from 0 to $\infty$; CLz/F, clearance rate calibrated by bioavailability.

In the animal model study, the relative bioavailability of $\mathrm{ECH}$ alone and ECH with combinations were evaluated, and the results show that the $\mathrm{ECH}$ oral bioavailability was elevated by verapamil and clove oil by nearly 1.37 -fold and 2.36 -fold when it compared to $\mathrm{ECH}$ alone. It is possible that the absorption and bioavailability of ECH could be further elevated when the $\mathrm{ECH}$, verapamil, and clove oil were combined.

\section{Conclusion}

Both in vitro and in situ intestinal absorption experiments consistently demonstrated that ECH absorption was poor and site dependent. In addition, ECH had higher absorption in small intestine than in colon and without segment specificity among small intestine. ECH was the substrate of $P$-gp, and jejunal absorption could be improved by using clove oil. The absorption mechanism(s) in jejunum may be carrier-mediated uptake/efflux pathways. Moreover, the improvement of intestinal permeability and absorption augment by clove oil and inhibiting $P$-gp-mediated efflux by verapamil could result in the oral bioavailability enhancement of ECH. Importantly, the influence on ECH intestinal absorption and oral bioavailability by its combination, with both verapamil and clove oil warrants further study, as well as the development of promising agent(s) for ECH bioavailability augment.

\section{Acknowledgments}

This research was supported by the Natural Science Foundation of Jiangsu province (No BK20140674), the National Natural Science Foundation of China (No 81403080), and the Fundamental Research Funds for the Central Universities.

\section{Disclosure}

The authors declare that there are no conflicts of interest in this work.

\section{References}

1. Li F, Yang Y, Zhu P, et al. Echinacoside promotes bone regeneration by increasing OPG/RANKL ratio in MC3T3-E1 cells. Fitoterapia. 2012; 83(8):1443-1450.

2. Yang X, Li F, Yang Y, et al. Efficacy and safety of echinacoside in a rat osteopenia model. Evid Based Complement Alternat Med. 2013;2013: 926-928.

3. He WJ, Fang TH, Ma X, Zhang K, Ma ZZ, Tu PF. Echinacoside elicits endothelium-dependent relaxation in rat aortic rings via an NO-cGMP pathway. Planta Med. 2009;75(13):1400-1404.

4. Zhu M, Lu C, Li W. Transient exposure to echinacoside is sufficient to activate Trk signaling and protect neuronal cells from rotenone. J Neurochem. 2013;124(4):571-580.

5. Feng XY, Zhu M, Zhang QQ, Chen YP, Li WW. Selective protection of nigral dopaminergic neurons by echinacoside in a rat model of Parkinson disease induced by rotenone. Zhong Xi Yi Jie He Xue Bao. 2012;10(7): 777-783.

6. Wu Y, Li L, Wen T, Li YQ. Protective effects of echinacoside on carbon tetrachloride-induced hepatotoxicity in rats. Toxicology. 2007; 232(1-2):50-56.

7. Jia C, Shi H, Jin W, et al. Metabolism of echinacoside, a good antioxidant, in rats: isolation and identification of its biliary metabolites. Drug Metab Dispos. 2009;37(2):431-438.

8. Jia C, Shi H, Wu X, Li Y, Chen J, Tu P. Determination of echinacoside in rat serum by reversed-phase high-performance liquid chromatography with ultraviolet detection and its application to pharmacokinetics and bioavailability. J Chromatogr B Analyt Technol Biomed Life Sci. 2006; 844(2):308-313.

9. Yu K, Chen F, Li C. Absorption, disposition, and pharmacokinetics of saponins from Chinese medicinal herbs: what do we know and what do we need to know more? Curr Drug Metab. 2012;13(5): 577-598.

10. Surampalli G, Nanjwade BK, Patil PA. Corroboration of naringin effects on the intestinal absorption and pharmacokinetic behavior of candesartan cilexetil solid dispersions using in-situ rat models. Drug Dev Ind Pharm. 2014:1-9.

11. Ahmed IS, Hassan MA, Kondo T. Effect of lyophilized grapefruit juice on $P$-glycoprotein-mediated drug transport in-vitro and in-vivo. Drug Dev Ind Pharm. 2013;41(3):375-381.

12. Engman H. Intestinal Barriers to Oral Drug Absorption Cytochrome P450 $3 A$ and ABC-Transport Proteins. Uppsala, Sweden: Faculty of Pharmacy, Uppsala University; 2003.

13. Xie Y, Zeng X, Li G, Cai Z, Ding N, Ji G. Assessment of intestinal absorption of total flavones of Hippophae rhamnoides L. in rat using in situ absorption models. Drug Dev Ind Pharm. 2010;36(7): 787-794.

14. Cheng J, Wu ZH, Ping QN, Wang B, Lu J. The absorption characteristics of bifendate solid dispersion in rat intestinal tissue. Drug Dev Ind Pharm. 2010;36(3):283-291. 
15. Cook TJ, Shenoy SS. Intestinal permeability of chlorpyrifos using the single-pass intestinal perfusion method in the rat. Toxicology. 2003; 184(2-3):125-133.

16. Li F, Yang X, Yang Y, Li P, Yang Z, Zhang C. Phospholipid complex as an approach for bioavailability enhancement of echinacoside. Drug Dev Ind Pharm. 2015:1-8.

17. Mazzaferro S, Bouchemal K, Skanji R, Gueutin C, Chacun H, Ponchel G. Intestinal permeation enhancement of docetaxel encapsulated into methyl-beta-cyclodextrin/poly(isobutylcyanoacrylate) nanoparticles coated with thiolated chitosan. J Control Release. 2012; 162(3):568-574.

18. Li F, Yang X, Yang Y, Li P, Yang Z, Zhang C. Phospholipid complex as an approach for bioavailability enhancement of echinacoside. Drug Dev Ind Pharm. 2015:1-8.

19. Cheng J, Wu ZH, Ping QN, Wang B, Lu J. The absorption characteristics of bifendate solid dispersion in rat intestinal tissue. Drug Dev Ind Pharm. 2010;36(3):283-291.

20. Stewart BH, Chan OH, Lu RH, et al. Comparison of intestinal permeabilities determined in multiple in vitro and in situ models: relationship to absorption in humans. Pharm Res. 1995;12(5):693-699.

21. Reis JM, Dezani AB, Pereira TM, Avdeef A, Serra CH. Lamivudine permeability study: a comparison between PAMPA, ex vivo and in situ single-pass intestinal perfusion (SPIP) in rat jejunum. Eur J Pharm Sci. 2013;48(4-5):781-789.

22. Thomson AB, Keelan M, Clandinin MT, Walker K. Dietary fat selectively alters transport properties of rat jejunum. J Clin Invest. 1986 77(1):279-288.
23. Curran PF, Schwartz GF. Na, Cl, and water transport by rat colon. J Gen Physiol. 1960;43:555-571.

24. Barthe L, Woodley J, Houin G. Gastrointestinal absorption of drugs: methods and studies. Fundam Clin Pharmacol. 1999;13(2):154-168.

25. Matthias A, Blanchfield JT, Penman KG, et al. Permeability studies of alkylamides and caffeic acid conjugates from echinacea using a Caco-2 cell monolayer model. J Clin Pharm Ther. 2004;29(1):7-13.

26. Stewart BH, Chan $\mathrm{OH}, \mathrm{Lu} \mathrm{RH}$, et al. Comparison of intestinal permeabilities determined in multiple in vitro and in situ models: relationship to absorption in humans. Pharm Res. 1995;12(5):693-699.

27. Reis JM, Dezani AB, Pereira TM, Avdeef A, Serra CH. Lamivudine permeability study: a comparison between PAMPA, ex vivo and in situ Single-Pass Intestinal Perfusion (SPIP) in rat jejunum. Eur J Pharm Sci. 2013;48(4-5):781-789.

28. Thomson AB, Keelan M, Clandinin MT, Walker K. Dietary fat selectively alters transport properties of rat jejunum. J Clin Invest. 1986;77(1): 279-288.

29. Curran PF, Schwartz GF. Na, Cl, and water transport by rat colon. J Gen Physiol. 1960;43:555-571.

30. Barthe L, Woodley J, Houin G. Gastrointestinal absorption of drugs: Methods and studies. Fundamental \& Clinical Pharmacology. 1999;13(2): 154-168.

31. Matthias A, Blanchfield JT, Penman KG, et al. Permeability studies of alkylamides and caffeic acid conjugates from echinacea using a Caco-2 cell monolayer model. J Clin Pharm Ther. 2004;29(1):7-13.
Drug Design, Development and Therapy

\section{Publish your work in this journal}

Drug Design, Development and Therapy is an international, peerreviewed open-access journal that spans the spectrum of drug design and development through to clinical applications. Clinical outcomes, patient safety, and programs for the development and effective, safe, and sustained use of medicines are a feature of the journal, which

\section{Dovepress}

has also been accepted for indexing on PubMed Central. The manuscript management system is completely online and includes a very quick and fair peer-review system, which is all easy to use. Visit http://www.dovepress.com/testimonials.php to read real quotes from published authors.

Submit your manuscript here: http://www.dovepress.com/drug-design-development-and-therapy-journal 